\title{
Preparation of human tau exon-2- and -10-specific monoclonal antibodies for the recognition of brain tau proteins in various mammals
}

\author{
CAO CHEN $^{1}$, YAN LV ${ }^{1}$, QI SHI ${ }^{1}$, BAO-YUN ZHANG ${ }^{1}$, LI-NA CHEN ${ }^{1}$, \\ $\mathrm{KANG} \mathrm{XIAO}^{1}$, JING SUN ${ }^{1}$ and XIAO-PING DONG ${ }^{1,2}$
}

\begin{abstract}
${ }^{1}$ State Key Laboratory for Infectious Disease Prevention and Control, Collaborative Innovation Center for Diagnosis and Treatment of Infectious Diseases (Zhejiang University), National Institute for Viral Disease Control and Prevention, Chinese Center for Disease Control and Prevention; ${ }^{2}$ Chinese Academy of Sciences Key Laboratory of Pathogenic Microbiology and Immunology, Institute of Microbiology, Chinese Academy of Sciences, Beijing, P.R. China
\end{abstract}

Received January 8, 2015; Accepted May 18, 2015

DOI: $10.3892 / \mathrm{ijmm} .2015 .2235$

\begin{abstract}
The aggregations of tau protein in brain tissue have been described in a large number of neurodegenerative diseases; however, due to the lack of tau isoform- or exon-specific antibodies, the exact situations under which various brain tau isoforms can be found and their exact contributions during disease progression remain unknown. Therefore, in this study, we prepared tau exon-specific monoclonal antibodies (mAbs) that recognize different mammalian tau isoforms. Briefly, $3 \mathrm{Balb} / \mathrm{c}$ mice were separately immunized ( 3 mice per antigen) with the recombinant GST-fusion proteins, GST-tE2 and GST-tE10. Two hybridoma cell lines, 4A8 and 3E12, secreting antibodies against human tau exon- 2 and -10 were established using the hybridoma technique. The sensitivity and specificity of the prepared mAbs were evaluated using indirect ELISA and western blot analysis. The ability of the prepared mAbs, $4 \mathrm{~A} 8$ and $3 \mathrm{E} 12$, to recognize endogenous tau protein in the brain tissues of various mammals was estimated by immunoprecipitation. Based on the results of various verification methods, we found that the prepared mAbs, 4A8 and 3E12, not only specifically reacted with the individual recombinant GST tau exon fusion proteins, but also correctly recognized the recombinant human tau isoforms containing respective exon sequences, as shown by western blot analysis. Furthermore, western blot analysis and immunoprecipitation assays verified that the mAbs, 4A8 and 3E12, recognized endogenous tau proteins in human brain tissue, as well as tau proteins in a series of mammalian tissues,
\end{abstract}

Correspondence to: Professor Xiao-Ping Dong, State Key Laboratory for Infectious Disease Prevention and Control, Collaborative Innovation Center for Diagnosis and Treatment of Infectious Diseases (Zhejiang University), National Institute for Viral Disease Control and Prevention, Chinese Center for Disease Control and Prevention, 155 Changbai Road, Beijing, P.R. China

E-mail: dongxp238@sina.com

Key words: tau isoform, exon-2, exon-10, monoclonal antibody, brain including goat, bovine, rabbit, hamster and mouse. Thus, in the present study, using the hybridoma technique, we successfully prepared the mAbs, 4A8 against tau exon-2 and 3E12 against tau exon-10, which provide useful tools for determining potential alternations of tau isoforms in neurodegenerative diseases.

\section{Introduction}

Tau, a microtubule-associated protein (MAP) has the ability to interact with tubulin, thus promoting the assembly of microtubules and structure stabilization (1). Human tau is coded for by a single gene on chromosome 17 , yielding several molecular isoforms due to alternative mRNA splicing (2). In the human brain, there are 6 tau isoforms based on different combinations of the presence or absence of inserts encoded by exon-2 (29-aa) and/or by exon-3 (29-aa) in the amino-terminal half, and a 31-aa repeat (R2) encoded by exon-10 in the carboxy-terminal half of the protein. Tau contains 3 repeat segments in the domain for microtubule-binding. Depending on the number of inserts/repeats, tau isoforms are also nominated as 0N4R/ tau383, 1N4R/tau412 and 2N4R/tau441 with 4 repeats, and as $0 \mathrm{~N} 3 \mathrm{R} / \mathrm{tau} 352,1 \mathrm{~N} 3 \mathrm{R} / \mathrm{tau} 381$ and $2 \mathrm{~N} 3 \mathrm{R} / \mathrm{tau} 410$ with 3 repeats. It has been suggested that tau isoforms containing 4 repeats are better at promoting microtubule assembly than those with 3 repeats (3). The smallest size tau isoform $(0 \mathrm{~N} 3 \mathrm{R} / \mathrm{tau} 352)$ is the only form that is expressed in the human fetal brain (1).

The aggregation of tau in brain tissue has been described in a large number of neurodegenerative diseases, such as Alzheimer's disease (AD), progressive supranuclear palsy (PSP), corticobasal degeneration (CBD), Pick's disease (PiD), prion disease $(\mathrm{PrD})$, and frontotemporal dementia and parkinsonism linked to chromosome 17 (FTDP-17); thus, these diseases have been classified as 'tauopathies' (4-7). However, the tau pathology among these disorders may vary greatly. For instance, all brain tau isoforms with a hyperphosphorylated state are the main component of the paired helical and straight filaments in $\mathrm{AD}(8-10)$, and tau isoforms with 3 repeats predominate in the neuronal deposits of PiD (11), whereas the filaments of PSP and $\mathrm{CBD}$ are composed of 4-repeat tau isoforms $(12,13)$. In addi- 
tion, filaments from human brains affected by tau pathology also exhibit a range of morphologies and specific conformers of aggregated tau may give rise to distinct tauopathies (6).

In a previous study, we prepared 3 tau exon-specific polyclonal antibodies which react against exon-2, -3 and -10 , respectively (14). Different disease-related tau profiles in cerebrospinal fluid (CSF) samples from patients suffering from sporadic Creutzfeldt-Jakob disease (sCJD) were observed in the antibody reactions against exon- 2 or -10 , suggesting the potential usage of these 2 antibodies in the further study of prion diseases, as well as in the study of other neurodegenerative disorders (14). In the present study, to obtain monoclonal antibodies (mAbs) against tau exon-2 and -10, purified recombinant GST-fusion proteins were separately immunized into Balb/c mice. Following cell fusion and selection, 2 strains of hybridomas that produced the antibody against exon- 2 or -10 of tau, respectively, were obtained. The specificities and sensitivities of the prepared mAbs were systematically analyzed. The tau patterns and characteristics of the brain tissues of various mammals were assessed in parallel with the prepared mAbs.

\section{Materials and methods}

Ethics statement. Human brain tissue was obtained from a healthy donor who was killed in a car accident at the age of 56, as previously described (15). The approval for its use was obtained from his next of kin following written informed consent and the approval of the Ethics Committee of the National Institute for Viral Disease Control and Prevention at the Chinese Center for Disease Control and Prevention (China CDC), Beijing, China. The animal tissues used in this study were approved by the Ethics Committee of the National Institute for Viral Disease Prevention and Control at the China CDC. Housing and experimental protocols were in accordance with the Chinese Regulations for the Administration of Affairs Concerning Experimental Animals.

Preparation of mouse $m A b s$ against tE2 and $t E 10$. The recombinant GST-fusion prokaryotic proteins, GST-tE2 and GST-tE10, which were used as antigens in the preparations of the $\mathrm{mAbs}$, were expressed and purified according to the protocol described in our previous study (16). One hundred micrograms of GST-tE2 or GST-tE10 were emulsified with an equal volume of Freund's complete adjuvant, and were immunized into 6- to 8-week-old Balb/c female mice by intraperitoneal injection (3 mice per antigen). Two weeks later, the animals were injected with a half-dose of each antigen $(50 \mu \mathrm{g})$ emulsified with an equal volume of Freund's incomplete adjuvant. A week later, blood samples were collected by cutting the mouse tails for measuring the presence of specific antibodies in sera. After the third immunization, blood was taken to monitor the induction of the specific antibody. The mice were administered a final booster of GST-tE2 or GST-tE10 (100 $\mu \mathrm{g}) 3$ days before the fusing program. When the serum titers reached $5 \times 10^{3}$ in a tau-specific ELISA, the mice were sacrificed under anesthesia with ether and their spleens were removed.

Splenocytes $\left(1 \times 10^{8}\right)$ were fused with $1 \times 10^{7} \mathrm{SP} 2 / 0$ myeloma cells in $45 \%$ polyethylene glycol (PEG). Hybridoma clones were screened in HAT medium (RPMI-1640 with 10\% FBS, $10 \mathrm{mM}$ sodium hypoxanthanine, $40 \mathrm{mM}$ aminopterin and $1.6 \mathrm{mM}$ thymidine). An indirect tau-exon specific ELISA was used to screen the secretion of the antibodies into the wells. The wells that were positive for GST-tE2 but negative for GST-tE10 were selected as positive wells for anti-tE2 and vice versa. The positive cells were subsequently subcloned twice with a limiting dilution procedure.

One week following treatment, the cloned hybridomas producing anti-tE2 and anti-tE10 were separately intraperitoneally injected into Balb/c mice with $0.5 \mathrm{ml}$ pristane (Sigma, St. Louis, MO, USA) per mouse. The animals were euthanized by ether 2-3 weeks post-injection when the transplant tumors formed and ascites were collected for antibody detection. The isotypes of the prepared antibodies were determined using the Mouse Monoclonal Antibody Isotyping kit (Roche, Basel, Switzerland; Cat. no. 11493027001). The sensitivities and specificities of the antibodies were examined by ELISA and western blot analysis.

Preparation of brain homogenates. Goat, bovine, rabbit, mouse and hamster brain samples were obtained from animals euthanized with ether. The brain tissue originated from a 56-year-old car accident victim. All brain samples were homogenized in $10 \%$ lysis buffer $(100 \mathrm{mM} \mathrm{NaCl}, 10 \mathrm{mM}$ EDTA, $0.5 \%$ Nonidet $\mathrm{P}-40,0.5 \% \mathrm{C}_{24} \mathrm{H}_{40} \mathrm{O}_{4} \cdot \mathrm{Na}, 10 \mathrm{mM}$ Tris, $\mathrm{pH}$ 7.5) according to the protocol used in the study by Zhang et al (17). Tissue debris was removed by low-speed centrifugation at 2,000 x g for $10 \mathrm{~min}$ and the supernatants were collected for further analysis.

Biotin labeling. The labeling of the prepared mAbs with biotin was conducted using a commercially supplied biotin label kit (EBLK0002; Elabscience Biotechnology Co. Ltd., Wuhan, China) according to the manufacturer's instructions. The final concentration of the biotin-labeled $\mathrm{mAb}$ was $1.5 \mathrm{mg} / \mathrm{ml}$.

ELISA. An indirect ELISA was established in order to examine the specificity and sensitivity of the selected mAbs. The fusion proteins, GST-tE2 or GST-tE10, were diluted to a final concentration of $1 \mu \mathrm{g} / \mathrm{ml}$ in PBS and coated onto 96-well microtiter plates overnight at $4^{\circ} \mathrm{C}$. After washing 3 times with PBST (phosphatebuffered saline, $\mathrm{pH} 7.6$, containing $0.05 \%$ Tween-20), the plates were blocked with $2 \% \mathrm{BSA}$ in PBST at $37^{\circ} \mathrm{C}$ for $2 \mathrm{~h}$ and then incubated with various dilutions of the tested sera, supernatants of the cloned hybridoma or ascites. After rinsing thoroughly with PBST 3 times, the possible captured mouse antibodies were further identified by horseradish peroxidase (HRP)-conjugated anti-mouse secondary antibody (Cat. no. 31430; Thermo Fisher Scientific, Inc., Waltham, MA, USA) at a $1: 10,000$ dilution at $37^{\circ} \mathrm{C}$ for $1 \mathrm{~h}$. Color was developed with 3,3',5,5'-tetramethylbenzidine (TMB; Sigma) as a substrate at $37^{\circ} \mathrm{C}$ for $30 \mathrm{~min}$. Absorbance was measured at $450 \mathrm{~nm}\left(\mathrm{~A}_{450 \mathrm{~nm}}\right)$ after quenching the wells by the addition of $2 \mathrm{M} \mathrm{H}_{2} \mathrm{SO}_{4}$. The titration of the tested samples was evaluated as positive when the $\mathrm{P}(\mathrm{n})$ value was $\geq 2.1$.

Immunoprecipitation (IP). In total, $200 \mu \mathrm{l}$ of $10 \%$ brain homogenates of the various mammals were incubated with Tau polyclonal anbitody (pAb; H-150; Cat. no. sc-5587; Santa Cruz Biotechnology, Santa Cruz, CA, USA) and $50 \mu$ l of Dynabeads ${ }^{\circledR}$ Protein G (Invitrogen, Waltham, MA, USA) at $4^{\circ} \mathrm{C}$ overnight. Additionally, $15 \mu \mathrm{l}$ of each $10 \%$ brain homogenate were used as input controls. The immunocomplexes were collected and washed 6 times with phosphate-buffered saline (PBS) containing 
A

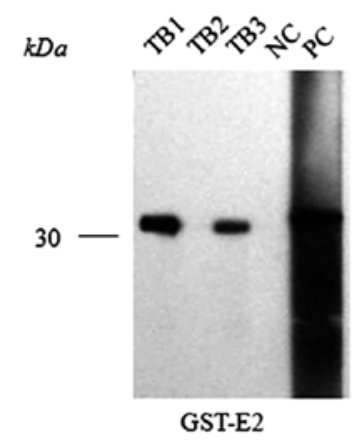

B

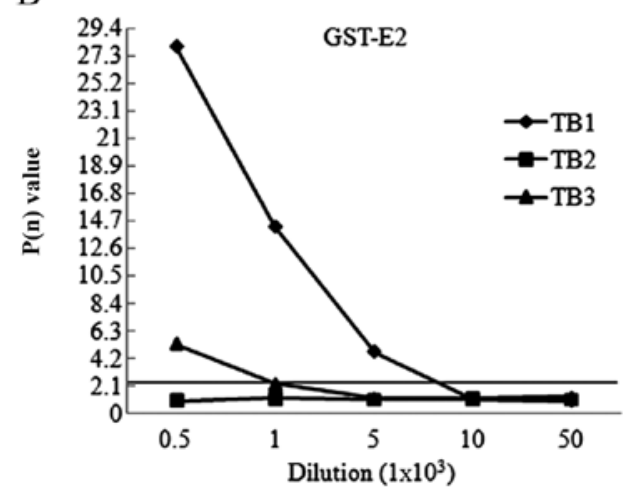

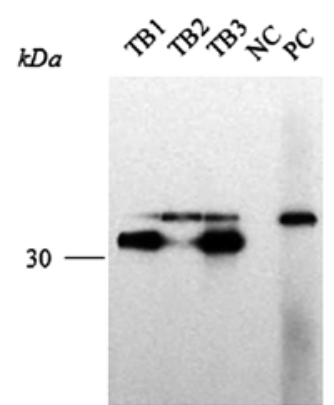

GST-E10

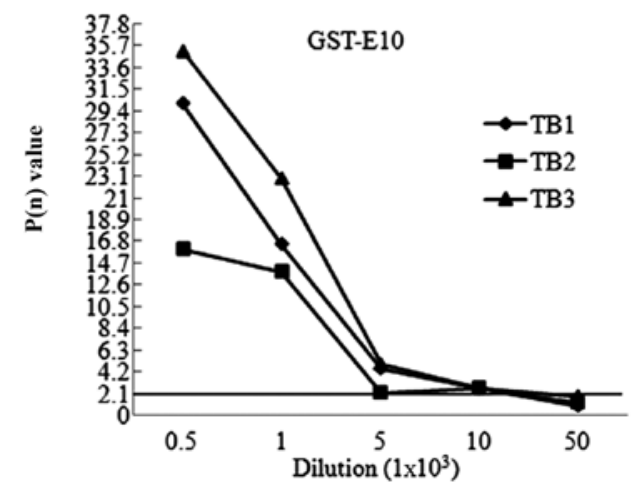

Figure 1. (A) Specificity tests of 3 serum samples from mouse tail blood by western blot analysis. Mouse numbers are indicated on the top of the blots. The purified proteins, GST-tE2 and GST-tE10, are marked below the blots. The relative molecular weights are shown on the left. Negative control, normal mouse serum; positive control; anti-GST-tE2 and anti-GST-tE10 rabbit serum, as previously described (14). (B) Sensitivity tests of 3 serum samples from mouse tail blood by an indirect ELISA coated with the purified GST-tE2 or GST-tE10. The x-axis represents the dilution of the antiserum and the y-axis represents the P/N values. The $\mathrm{P}(\mathrm{n})$ value 2.1 is illustrated by a solid line.

$0.02 \%$ Tween-20, supplemented with $50 \mu 1 \mathrm{X}$ loading buffer and heated in boiling water for $10 \mathrm{~min}$. Protein $\mathrm{G}$ beads were removed with a magnetic shelf (Invitrogen). The eluted products and the inputs were separated with $12 \%$ SDS-polyacrylamide gelelectrophoresis (SDS-PAGE), and subsequently detected by the biotin-labeled $\mathrm{mAb} 3 \mathrm{E} 12$ - or $4 \mathrm{~A} 8$-specific western blot analysis.

Western blot analysis. The analysis of the expression and purification of the GST-tau-exon-fusion proteins, including GST-tE2, GST-tE3 and GST-tE10, as well as 6 tau isoforms including tau441, tau412, tau383, tau410, tau381 and tau352, were conducted as previously described (14). GST-tau-exonfusion proteins were separated by $15 \%$ SDS-PAGE, while the tau isoforms and brain homogenates of various mammals were separated in 12\% SDS-PAGE. Following electrotransfer onto PVDF membranes (Millipore, Billerica, MA, USA) using a semi-dry blotting system (Bio-Rad Laboratories, Hercules, CA, USA), the membranes were blocked with 5\% dried non-fat milk in PBS and incubated with various primary antibodies at $4^{\circ} \mathrm{C}$ overnight, including 1:1,000 diluted mAb tau-13 and pAb Tau (H-150) (Cat. no. sc-5587; Santa Cruz Biotechnology) and 1:1,000 diluted prepared mAb anti-tE2 (4A8) or anti-tE10 (3E12). Subsequently, after washing with TBS containing Tween-20 (TBST, $10 \mathrm{mM}$ Tris-HCl, $133 \mathrm{mM} \mathrm{NaCl}, \mathrm{pH}$ 7.4), the blots were incubated with 1:10,000 diluted HRP-conjugated secondary antibody (Thermo Fisher Scientific). After washing with TBST, the reactive signals were visualized by an enhanced chemiluminescence (ECL) kit (PE Applied Biosystems, Foster City, CA, USA). Images were captured using a ChemiDoc ${ }^{\mathrm{TM}}$ XRS+ Imager (Bio-Rad Laboratories) and quantified using NIH ImageJ software. The signals were normalized to the loading controls.

\section{Results}

Preparations of murine $m A$ bs against $t E 2$ and $t E 10$. To prepare the specific $m A$ bs against the fragments encoded by exon-2 and exon-10 of human tau, the Balb/c mice were separately immunized with the purified recombinant GST-fusion proteins, GST-tE2 or GST-tE10. Following two immunizations, blood samples were collected from the mouse tails and the presence of the specific antibodies was evaluated by an indirect ELISA coated with tau exon proteins. In total, 1 out of 3 GST-tE2immunized mice and 2 out 3 GST-tE10-immunized mice showed positive immunoreactivities $(\mathrm{P}(\mathrm{n})>2.1$ at the dilution of 1:1,000) (Fig. 1). Through the procedures of cell fusion and multiple clone selections, dozens of hybridoma cell clones producing antibodies against either tE2 or tE10 were selected. Western blot analysis revealed that the supernatants of the selected cell clones reacted specifically with the individual GST-tE2 or GST-tE10 fusion proteins (Fig. 2). Further indirect ELISA highlighted that the hybridoma clone 4A8 showed the highest anti-tE2 titer and that clone 3E12 showed the highest anti-tE10 titer (data not shown). Mouse ascites were prepared by intraperitoneal injections of these 2 hybridoma cells.

Determinations of the tau exon $m A b s, 4 A 8$ and $3 E 12$. To examine the sensitivities and specificities of the anti-tE2 mAb, 


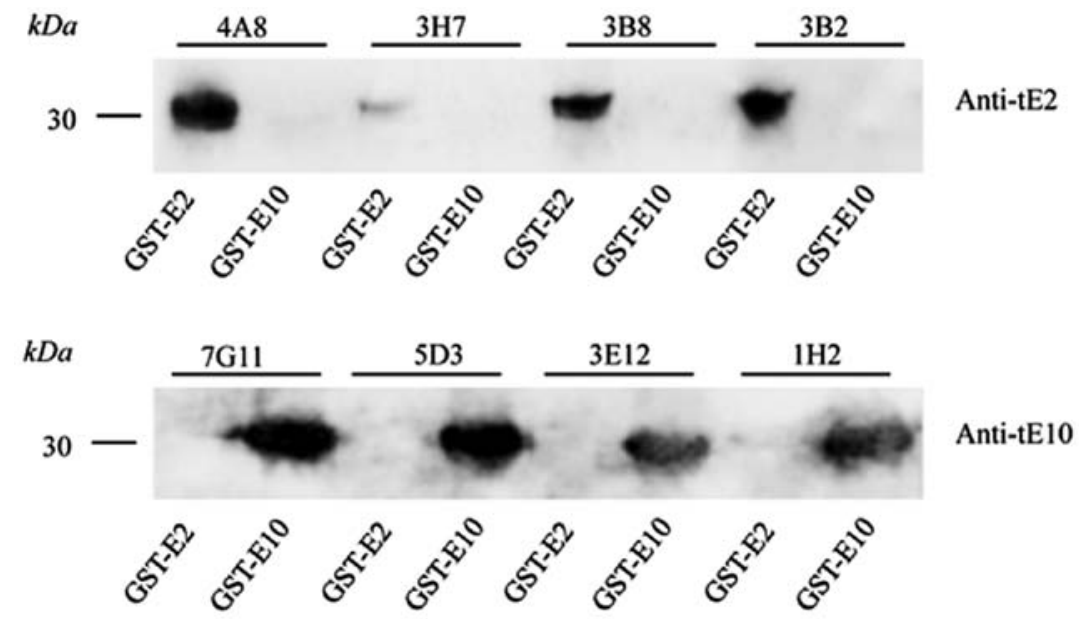

Figure 2. Specificity tests of the supernatants of the selected cell clones by western blot analysis. Various hybridoma cell clones against tE2 or tE10 are indicated on the top of the blots. The purified proteins, GST-tE2 and GST-tE10, are marked below the blots. The relative molecular weights are shown on the left.
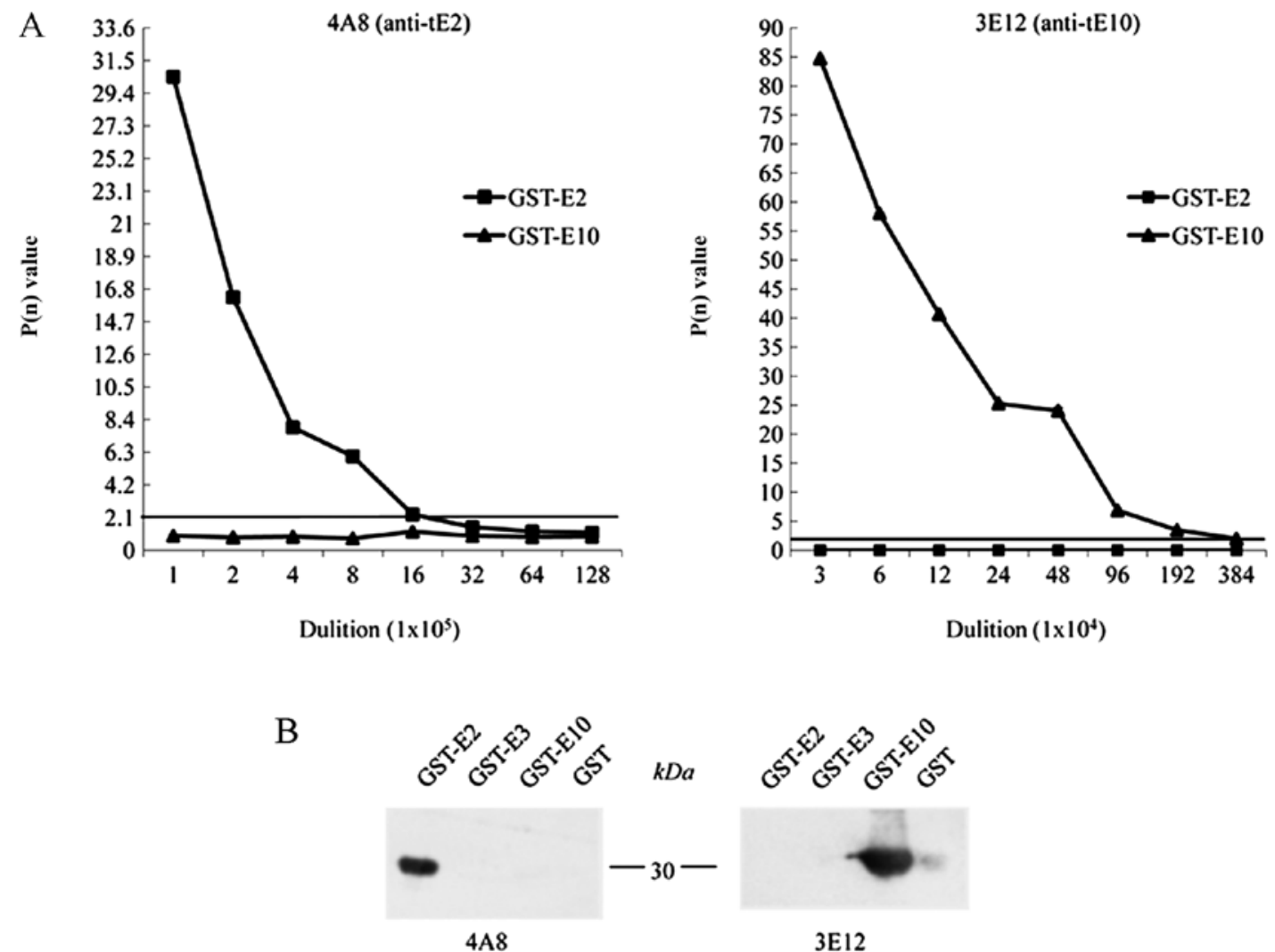

Figure 3. Evaluation of the sensitivity and specificity for the prepared mAbs. (A) Indirect ELISA. Equal amounts of the purified GST-tE2 and GST-tE10 were coated as the antigens. The $x$-axis represents the dilution of the tested mAbs and the $y$-axis represents the $P(n)$ values. The $P(n)$ value 2.1 is illustrated by a solid line. (B) Western blot analysis. Recombinant GST, GST-tE2, GST-tE3 and GST-tE10 were separated in 15\% SDS-PAGE and transferred onto PVDF membranes as the detecting antigens (indicated on the top of the blots). The tested mAbs 4A8 and 3E12 were used as the primary antibodies (indicated below). The relative molecular weights of these GST-fusion proteins are shown between the 2 blots.

4A8, and the anti-tE10, mAb 3E12, the prepared ascites were subjected to an indirect ELISA coated with equal amounts of the purified GST-tE2 and GST-tE10. The results revealed that the mAb 4A8 reacted only with GST-tE2, while 3E12 reacted only with GST-tE10, again revealing their reliable immune specificities. Based on the rule of a $\mathrm{P}(\mathrm{n})$ value $\geq 2.1$, the ELISA titers of the mAbs, 4A8 and 3E12, with the individual recombinant proteins reached $1.6 \times 10^{6}$ and $1.9 \times 10^{6}$, respectively (Fig. 3A).
Furthermore, the specificities of the mAbs, 4A8 and 3E12, were examined by western blot analysis containing the purified recombinant proteins, GST-tE2, GST-tE3 and GST-tE10. At the dilution of 1:500 ascites, only GST-tE2 in the reaction of $\mathrm{mAb} 4 \mathrm{~A} 8$ and GST-tE10 in that of mAb 3E10 showed positive signals at the expected positions (Fig. 3B). No cross-reaction was identified with the other tau exon fusion proteins or GST protein under this experimental condition. 
A

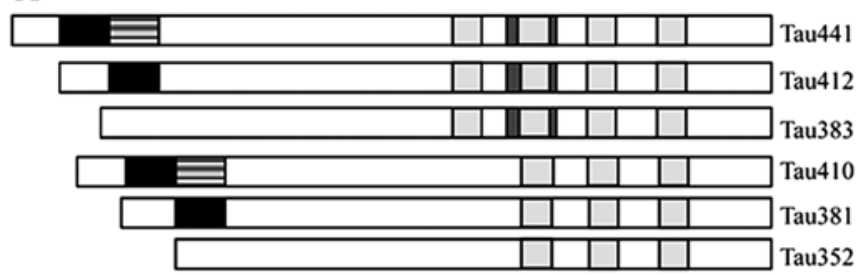

$\begin{array}{llll}\mathbf{E}_{\mathrm{E} 2} & \mathrm{G}_{\mathrm{E} 3} & \square_{\mathrm{E} 10} & \square_{\mathrm{R}}\end{array}$

B

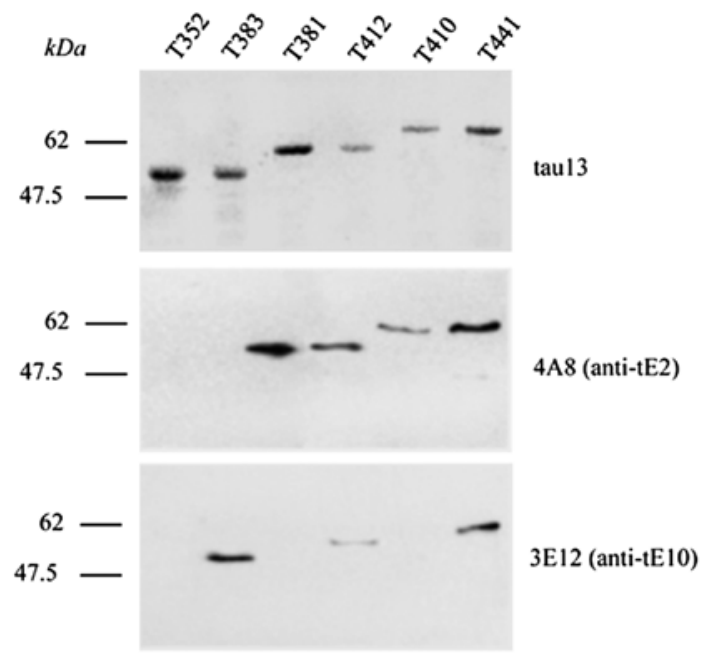

Figure 4. Immunoreactivities of the tau exon-specific mAbs with 6 recombinant human tau isoforms. (A) Schematic representation of 6 human tau isoforms. (B) Western blot analysis of the prepared mAbs with 6 recombinant human tau proteins. A commercial tau mAb tau-13 was used as the control. The blots with various antibodies are indicated on the right. Different tau isoforms are shown on the top of the blots. The relative molecular weights are shown on the left.

Using the commercial mouse $\mathrm{mAb}$ isotyping kit, the $\mathrm{tE} 2$ $\mathrm{mAb}, 4 \mathrm{~A} 8$, was identified as $\mathrm{IgG}_{2 \mathrm{~b}}, \kappa$ chain and the $\mathrm{tE} 10 \mathrm{mAb}$, $3 \mathrm{E} 12$, as $\operatorname{IgG}_{1}$, $\kappa$ chain.

Specific recognition of the tau exon $m A b s, 4 A 8$ and 3E12, with the corresponding recombinant tau isoforms. Six human tau isoforms have been addressed, varying on the basis of different tau exon segment insertions and the number of repeated regions (1). The schematic structures of the 6 tau isoforms are presented in Fig. 4A. To prove the recognitions of the prepared tau exon mAbs, $4 \mathrm{~A} 8$ and $3 \mathrm{E} 12$, on various tau isoforms in the context of a full-length protein, the 6 purified human tau isoforms were reacted with the prepared tau exon mAbs, as well as a commercial $\mathrm{mAb}$, tau-13, able to recognize all isoforms in a western blot analysis. As observed previously, all 6 tau isoforms were detectable in the reaction with mAb tau-13, mobilizing from 48 to $67 \mathrm{kDa}$ (Fig. 4B, upper panel). Four tau isoforms containing exon-2 domain (tau-381,-412, -410 and -441) showed positive bands in the reaction with $\mathrm{mAb} 4 \mathrm{~A} 8$ (Fig. 4B, middle panel), while 3 containing the exon-10 domain (tau-383, -412 and -441) positively reacted with $\mathrm{mAb} 3 \mathrm{E} 12$ (Fig. 4B, lower panel). No false- or cross-reaction was observed between the 2 prepared $\mathrm{mAbs}$, suggesting reliable specificities of the mAbs, $4 \mathrm{~A} 8$ and $3 \mathrm{E} 12$, in recognizing the relevant tau isoforms in the context of full-length proteins.

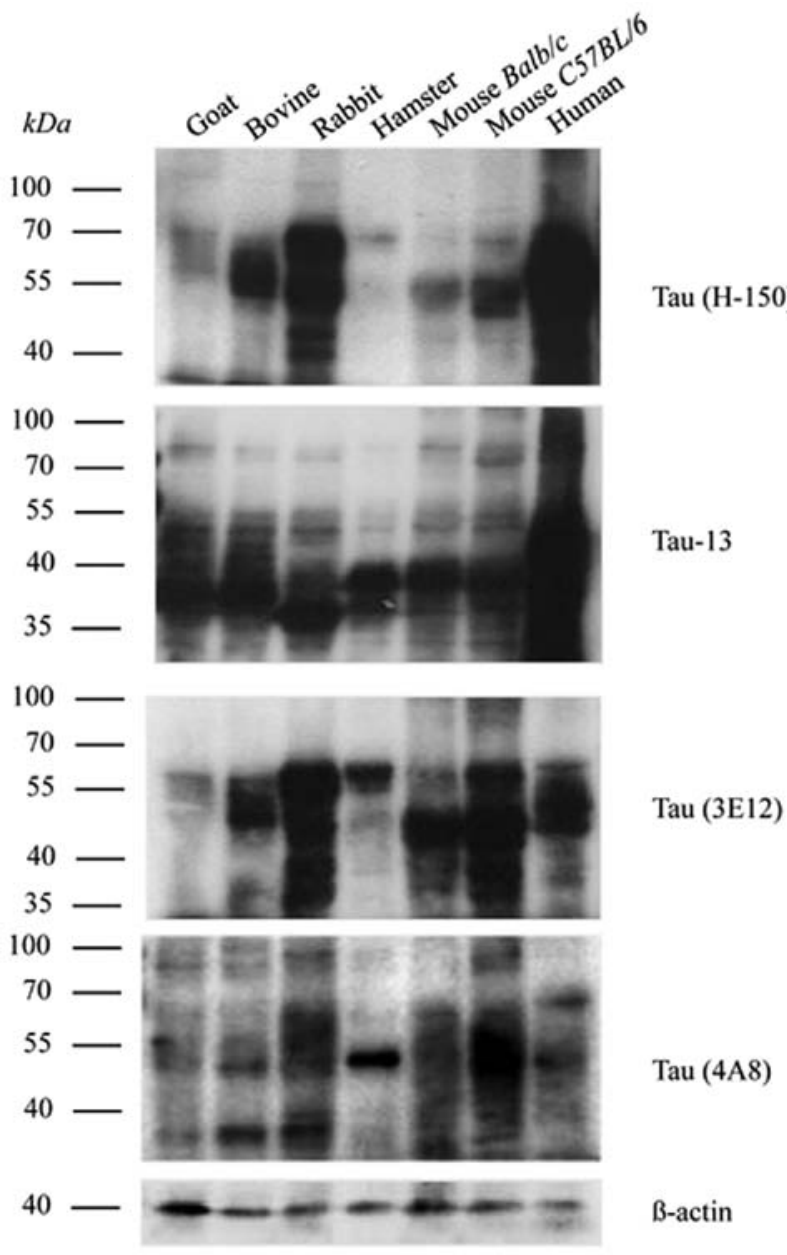

Figure 5. The reactive profiles of tau in the brains of various mammals by western blot analysis. Various mammalian brains are indicated on the top. The reactions with tau (H-150), tau-13, 4A8, 3E12 and $\beta$-actin are shown on the right. The relative molecular weights are indicated on the left.

Recognition of the tau exon mAbs, $4 A 8$ and 3E12, with endogenous brain tau proteins from a series of mammals. To examine the immunoreactivities of the prepared tau exon mAbs with endogenous tau proteins, brain homogenates of human origin and various mammals comprising goat, bovine, rabbit, mouse (strains Balb/c and C57BL/6) and hamster tissues were prepared and run on a western blot analysis with the mAbs, 4A8 and $3 \mathrm{E} 12$, as well as with the commercial mouse-derived $\mathrm{mAb}$, tau-13, and the rabbit-derived pAb, tau (H-150), respectively. As shown in Fig. 5, numerous bands were detected in the reactions with the mAb tau-13 and pAb tau ( $\mathrm{H}-150)$, ranging from 45 to $70 \mathrm{kDa}$. Generally, the profiles of the immunoreactivities of mAb tau-13 and pAb tau (H-150) in the brain tissues of the tested mammals were similar, indicating a conserved feature of tau. However, the tau signal intensities among the tested samples varied significantly.

The prepared tau exon mAbs, 4A8 and 3E12, resulted in clear reactive bands with human brain homogenates, ranging from 45-70 kDa (Fig. 5). Positive signals were also detected at positions $<40 \mathrm{kDa}$. Similar reactive patterns were also observed in the preparations of other tested samples, with the difference in the signal intensities among species. These data highlight that our prepared tau exon specific mAbs may recog- 

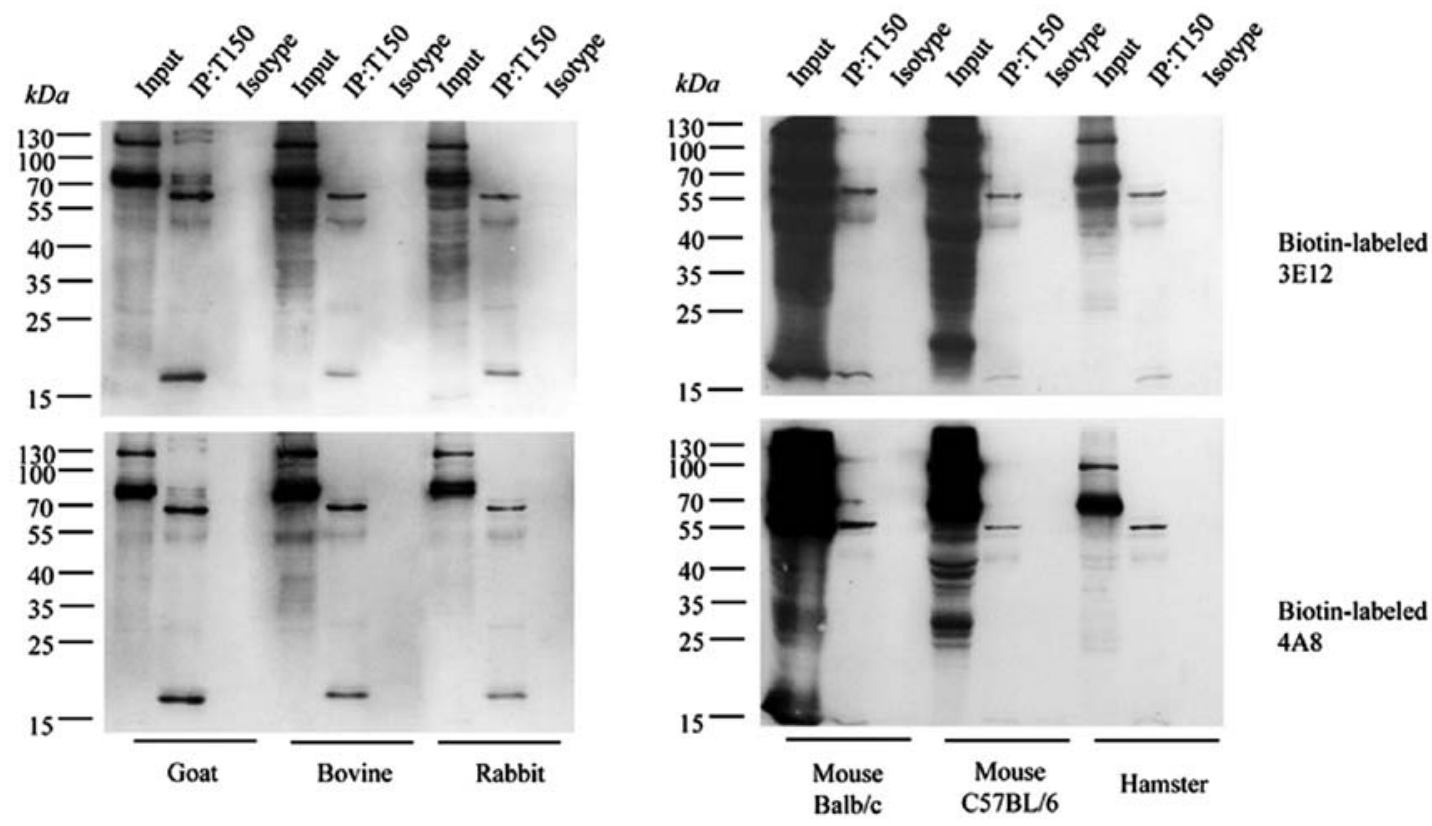

Figure 6. Immunoprecipitation assays for the endogenous tau in the brain homogenates of various mammals. Various mammalian brain homogenates were precipitated with tau (H-150) or rabbit IgG and subsequently evaluated by western blot analyis with biotin-labeled 3E12 (upper panels) or 4A8 (lower panels). Various mammalian brain homogenates (marked as input) were directly loaded into SDS-PAGE as controls. Various mammalian brain homogenates are marked on the bottom. Biotin-labeled 4A8 and 3E12 are shown on the right. The relative molecular weights are indicated on the left.

nize endogenous tau proteins not only in humans, but also in brain tissue from various mammalian sources.

Reliable specificity of the tau exon $m A b s, 4 A 8$ and $3 E 12$, with endogenous brain tau proteins. To further assess the specificities of the prepared tau exon mAbs in the recognition of endogenous brain tau proteins, immunoprecipitation assays were conducted with brain homogenates from goat, bovine, rabbit, hamster and mouse. To exclude the possibility of cross-reaction of the IgG heavy-chain due to the HRP-labeled secondary antibody during immunoprecipitation, the tau exon mAbs, 4A8 and 3E12, were separately labeled by biotin with the help of a commercial labeling kit. The brain homogenates were first precipitated with pAb tau (H-150) and blotted with the biotin-labeled mAbs, 4A8 and 3E12. As shown in Fig. 6, 2 predominately reactive bands that were roughly 65 and $55 \mathrm{kDa}$ were observed in all the precipitated products from all tested samples, while a detectable signal was observed in the preparations precipitated with rabbit $\mathrm{IgG}$ as the isotype antibody. These 2 positive bands coincided well with the taureactive bands in the brain extracts used as controls. Besides these 2 bands, a smaller band (approximately $17 \mathrm{kDa}$ ) was also identified in all reactions, while several larger specific bands were also seen in some reactions (Fig. 6). The reactive patterns in the precipitated products were quite comparable among the tested animals. These data indicate that the tau exon mAbs, $4 \mathrm{~A} 8$ and $3 \mathrm{E} 12$, possess reliable specificity in the recognition of endogenous brain tau proteins.

\section{Discussion}

Using a classic hybridoma technique with the recombinant human tau fusion proteins, GST-tE2 and GST-tE10, as immunogens, we created 2 hybridoma cell lines that secrete tau exon-specific mAbs against tau exon-2 (mAb 4A8) and exon-10 (mAb 3E12). We confirmed that our prepared mAbs correctly recognize recombinant human tau proteins that contain corresponding exons by western blot analysis. Both two tau exons contain only 29 and 31 amino acids. These two small segments seem to have strong immunogenicity in the form of GST-fusion protein, both exon-2 and -10 efficiently elicit high antibody titer when immunized into mice. On the other hand, our data verified that there was no detectable cross-reaction between these 2 antibodies. Analysis of the sequences of these exons indicated that, although the molecular weights of the peptides encoded by these 2 exons were quite similar, the sequences of each exon varied greatly (Fig. 7). This trait may supply the molecular basis for preparing individual specific antibodies.

Our tau exon mAbs showed a wide range of immunoreactivity among different mammalian species. As a conserved protein (2), the peptide sequences of tau exon-2 and -10 also share homology among human and various mammals. The screening of tau sequences of relevant mammals confirmed that the N-terminus of exon- 2 in humans and various mammals only differed by 2-5 amino acids, while the exon-10 did not differ at all (Fig. 7). The high homology in the peptide sequences of tau exon-2 and -10 supplies the molecular basis for the wide range of recognition of the mAbs, $4 \mathrm{~A} 8$ and $3 \mathrm{E} 12$, to the endogenous tau proteins among the tested mammals.

Tau proteins may present different isoforms in mammalian tissues, based on the different components of the repeat segments (2). In humans, 6 tau isoforms have been addressed, ranging from 352 to 441 amino acids in length (1). Studies have suggested the presence of 5 tau isoforms in mice, 4 in bovines and 2 in goats $(18,19)$, ranging from 341 to 448 amino acids in length (Table I). Relevant data for rabbits and hamsters is relatively limited (Table I). However, the majority of tau isoforms contain segments of exon- 2 and/or -10 , which may help to 
Exon-2

Homo sapiens
Bos taurus
Capra hircus
Oryctolagus cuniculus
Mus musculus
Mesocricetus auratus

ESPLQTPTEDGSEEPGSETSDAKSTPTAE
ESPLQTPADDGSEEPGSETSDAKSTPTAE
ESPLQTPADDGSEEPGSETSDAKSTPTAE
ESPLQTPADDGSEEPGSETSDAKSTPTAE
ESPPQPPADDGAEEPGSETSDAKSTPTAE
ASPPQPPADDGSEEPGSETSDAKSTPTAE

Exon-10

Homo sapiens

\begin{tabular}{|l}
\hline VQIINKKLDLSNVQSKCGSKDNIKHVPGGGS \\
VQIINKKLDLSNVQSKCGSKDNIKHVPGGGS \\
VQIINKKLDLSNVQSKCGSKDNIKHVPGGGS \\
VQIINKKLDLSNVQSKCGSKDNIKHVPGGGS \\
VQIINKKLDLSNVQSKCGSKDNIKHVPGGGS \\
VQIINKKLDLSNVQSKCGSKDNIKHVPGGGS
\end{tabular}

Figure 7. Homology comparison of the peptide sequences of tau exon-2 and -10 among humans and various mammals.

Table I. Homology comparison of exon-2 and -10 of different tau isoforms among humans and various mammals according to published studies.

\begin{tabular}{|c|c|c|c|c|c|}
\hline \multirow[b]{2}{*}{ Species } & \multirow[b]{2}{*}{ Accession no. } & \multirow{2}{*}{$\begin{array}{l}\text { No. of } \\
\text { amino } \\
\text { acids }\end{array}$} & \multicolumn{2}{|c|}{$\begin{array}{l}\text { Contain/similar } \\
\text { to the sequence } \\
\text { of human-derived }\end{array}$} & \multirow[b]{2}{*}{ Comments } \\
\hline & & & Exon-2 & Exon-10 & \\
\hline $\begin{array}{l}\text { Goat } \\
\text { (Capra hircus) }\end{array}$ & O02828 & 403 & $\sqrt{ }$ & $\sqrt{ }$ & $\begin{array}{l}\text { Isoform A: contain exon of } 1,4,5,7,9,11,12,13 \\
\text { Isoform B: contain exon of } 1,2,4,5,7,9,10,11,12,13 \\
\text { Nelson } \text { et al (19) }\end{array}$ \\
\hline $\begin{array}{l}\text { Bovine } \\
\text { (Bos taurus) }\end{array}$ & NP_776531 & 448 & $\sqrt{ }$ & $\sqrt{ }$ & $\begin{array}{l}\text { Isoform A: } 1,2,4,5,7,9,11,12,13 \\
\text { Isoform B: } 1,2,4,5,7,9,10,11,12,13 \\
\text { Isoform C: } 1,2,3,4,5,7,9,11,12,13 \\
\text { Isoform D: } 1,2,3,4,5,7,9,10,11,12,13 \\
\text { Himmler (18) }\end{array}$ \\
\hline $\begin{array}{l}\text { Rabbit } \\
\text { (Oryctolagus cuniculus) }\end{array}$ & XP_008269868 & 840 & $\sqrt{ }$ & $\sqrt{ }$ & Predicted sequence from NCBI \\
\hline $\begin{array}{l}\text { Mouse } \\
\text { (Mus musculus) }\end{array}$ & $\begin{array}{l}\text { NP_001033698 } \\
\text { NP_034968 } \\
\text { NP_001272383 } \\
\text { NP_001272384 } \\
\text { NP_001272385 }\end{array}$ & $\begin{array}{l}430 \\
372 \\
364 \\
350 \\
341\end{array}$ & $\begin{array}{l}x \\
\sqrt{ } \\
x \\
x \\
x\end{array}$ & $\begin{array}{l}\sqrt{ } \\
\sqrt{ } \\
x \\
\sqrt{ } \\
x\end{array}$ & $\begin{array}{l}\text { Isoform a } \\
\text { Isoform b } \\
\text { Isoform c } \\
\text { Isoform d } \\
\text { Isoform e }\end{array}$ \\
\hline $\begin{array}{l}\text { Hamster } \\
\text { (Mesocricetus auratus) }\end{array}$ & NP_001268808 & 432 & $\sqrt{ }$ & $\sqrt{ }$ & \\
\hline
\end{tabular}


explain the presence of multiple reactive tau bands in western blots with the prepared tau exon mAbs. Cellular tau protein undergoes post-translational modification under physiological conditions, i.e., phosphorylation $(1,2)$. The common phosphorylating sites within human tau are believed to be located at the tubulin binding region, including Ser-202/Thr-205, Ser-214/Ser-212, Thr-231/Ser-235 and Ser-396/Ser-404 (20). Thereby, the apparent molecular weights of tau in tissue usually vary greatly $(14,21)$, which leads to more than expected tau-specific bands in western blot analysis with tau-specific antibodies. Therefore, it is difficult to distinguish the endogenous tau isoforms in tissues based on their diversity in molecular weights, such as by western blot analysis, without complete dephosphorylation. In the reactions with commercial tau mAb tau-13 and pAb tau (H-150) in western blot analysis, some smaller $(<40 \mathrm{kDa})$ positive reactive bands were also detected in the brain tissues with tau-exon mAbs 4A8 and $3 \mathrm{E} 12$, suggesting that apart from mature tau proteins, there are numerous truncated tau proteins containing exon-2 and/or-10 in brain tissues.

The presence of tau isoforms in human brains may also vary distinctly depending on different physiological and pathological situations. Physiologically, the amounts of 3R-tau and 4R-tau are comparable in the adult cerebral cortex, while $0 \mathrm{~N}$-tau is predominant in developing brains (1). In many neurodegenerative diseases, tau may conform to different patterns. In AD, the neuronal fibrillary tangles (NFTs) are made up of paired helical filaments (PHFs) comprised of hyperphosphorylated tau, which are composed of six central nervous system tau isoforms $(2,8)$. In Down syndrome, tau is hyperphosphorylated yielding a pattern similar to that of $\mathrm{AD}(2)$. In CBD, tau is also present in the hyperphosphorylated form, but only approximately 68 and $64 \mathrm{kDa}$ are detectable by electrophoresis (1). In FTDP-17, tau inclusions are observed both in neurons and in glial cells, with 2 types of hyperphosphrylated tau forms (22). Due to the lack of tau isoform- or exon-specific antibodies, the exact situations under which various brain tau isoforms can be found and their exact contributions during disease progression remain unknown. Therefore, the tau exon-specific mAbs prepared in the present study may provide potentially useful materials for tau profile assays in the brains of humans and other mammals, physiologically and pathologically.

\section{Acknowledgements}

The present study was supported by grants from the Chinese National Natural Science Foundation Grants (81401670, 81100980), the China Mega-Project for Infectious Disease (2011ZX10004-101, 2012ZX10004215) and the SKLID Development Grant (2012SKLID102, 2011SKLID104).

\section{References}

1. Goedert M: Tau protein and neurodegeneration. Semin Cell Dev Biol 15: 45-49, 2004.

2. Avila J, Lucas JJ, Perez M and Hernandez F: Role of tau protein in both physiological and pathological conditions. Physiol Rev 84: 361-384, 2004.

3. Goedert M and Jakes R: Expression of separate isoforms of human tau protein: correlation with the tau pattern in brain and effects on tubulin polymerization. EMBO J 9: 4225-4230, 1990.
4. Williams DR: Tauopathies: classification and clinical update on neurodegenerative diseases associated with microtubuleassociated protein tau. Intern Med J 36: 652-660, 2006.

5. Lee VM, Goedert M and Trojanowski JQ: Neurodegenerative tauopathies. Annu Rev Neurosci 24: 1121-1159, 2001.

6. Hernández F and Avila J: Tauopathies. Cell Mol Life Sci 64: 2219-2233, 2007.

7. Giaccone G, Mangieri M, Capobianco R, Limido L, Hauw JJ, Haïk S, Fociani P, Bugiani O and Tagliavini F: Tauopathy in human and experimental variant Creutzfeldt-Jakob disease. Neurobiol Aging 29: 1864-1873, 2008.

8. Alonso AD, Zaidi T, Novak M, Barra HS, Grundke-Iqbal I and Iqbal K: Interaction of tau isoforms with Alzheimer's disease abnormally hyperphosphorylated tau and in vitro phosphorylation into the disease-like protein. J Biol Chem 276: 37967-37973, 2001.

9. Sjögren M, Davidsson P, Tullberg M, Minthon L, Wallin A, Wikkelso C, Granérus AK, Vanderstichele H, Vanmechelen E and Blennow K: Both total and phosphorylated tau are increased in Alzheimer's disease. J Neurol Neurosurg Psychiatry 70: 624-630, 2001.

10. Hampel H, Blennow K, Shaw LM, Hoessler YC, Zetterberg H and Trojanowski JQ: Total and phosphorylated tau protein as biological markers of Alzheimer's disease. Exp Gerontol 45: 30-40, 2010.

11. Delacourte A, Robitaille Y, Sergeant N, Buée L, Hof PR, Wattez A, Laroche-Cholette A, Mathieu J, Chagnon P and Gauvreau D: Specific pathological Tau protein variants characterize Pick's disease. J Neuropathol Exp Neurol 55: 159-168, 1996.

12. Flament S, Delacourte A, Verny M, Hauw JJ and Javoy-Agid F: Abnormal Tau proteins in progressive supranuclear palsy. Similarities and differences with the neurofibrillary degeneration of the Alzheimer type. Acta Neuropathol 81: 591-596, 1991.

13. Ksiezak-Reding H, Morgan K, Mattiace LA, Davies P, Liu WK, Yen SH, Weidenheim K and Dickson DW: Ultrastructure and biochemical composition of paired helical filaments in corticobasal degeneration. Am J Pathol 145: 1496-1508, 1994.

14. Chen C, Shi Q, Zhang BY, Wang GR, Zhou W, Gao C, Tian C, Mei GY, Han YL, Han J and Dong XP: The prepared tau exonspecific antibodies revealed distinct profiles of tau in CSF of the patients with Creutzfeldt-Jakob disease. PLoS One 5: e11886, 2010.

15. Shi Q, Xie WL, Zhang B, Chen LN, Xu Y, Wang K, Ren K, Zhang XM, Chen C, Zhang J and Dong XP: Brain microglia were activated in sporadic CJD but almost unchanged in fatal familial insomnia and G114V genetic CJD. Virol J 10: 216, 2013.

16. Gao C, Lei YJ, Han J, Shi Q, Chen L, Guo Y, Gao YJ, Chen JM, Jiang HY, Zhou W and Dong XP: Recombinant neural protein PrP can bind with both recombinant and native apolipoprotein E in vitro. Acta Biochim Biophys Sin (Shanghai) 38: 593-601, 2006.

17. Zhang J, Chen L, Zhang BY, Han J, Xiao XL, Tian HY, Li BL, Gao C, Gao JM, Zhou XB, et al: Comparison study on clinical and neuropathological characteristics of hamsters inoculated with scrapie strain $263 \mathrm{~K}$ in different challenging pathways. Biomed Environ Sci 17: 65-78, 2004.

18. Himmler A: Structure of the bovine tau gene: Alternatively spliced transcripts generate a protein family. Mol Cell Biol 9: 1389-1396, 1989.

19. Nelson PT, Stefansson K, Gulcher J and Saper CB: Molecular evolution of tau protein: implications for Alzheimer's disease. $\mathbf{J}$ Neurochem 67: 1622-1632, 1996.

20. Buée L, Bussière T, Buée-Scherrer V, Delacourte A and Hof PR: Tau protein isoforms, phosphorylation and role in neurodegenerative disorders. Brain Res Brain Res Rev 33: 95-130, 2000.

21. Goedert M, Spillantini MG, Potier MC, Ulrich J and Crowther RA: Cloning and sequencing of the cDNA encoding an isoform of microtubule-associated protein tau containing four tandem repeats: Differential expression of tau protein mRNAs in human brain. EMBO J 8: 393-399, 1989.

22. Hong M, Zhukareva V, Vogelsberg-Ragaglia V, Wszolek Z, Reed L, Miller BI, Geschwind DH, Bird TD, McKeel D, Goate A, et al: Mutation-specific functional impairments in distinct tau isoforms of hereditary FTDP-17. Science 282: 1914-1917, 1998. 